\title{
Effects of internal migration on the human settlements system in Latin America and the Caribbean
}

\author{
Jorge Rodríguez Vignoli
}

\begin{abstract}
The gradual abatement of rural-urban migration in Latin America and the Caribbean is leading to growing prevalence of migration between cities, a phenomenon about which little theory or empirical studies have been developed in the region. Accordingly, this work uses census microdata - the only source available in the region for estimating migration between cities - from a dozen countries to: (i) estimate the recent evolution of this migration using categories based on cities' population size (including a residual category that groups municipalities without cities); (ii) estimate the effect of this migration on the composition by sex, age, and education level of these categories of city, and (iii) evaluate in a general and preliminary manner the two-way links between the socioeconomic conditions of cities and the magnitude and effects of migration.
\end{abstract}

\section{Keywords}

Internal migration, human settlements, cities, population composition, quality of life, population censuses, migration statistics, Latin America and the Caribbean

\section{JEL classification}

R23, P25, 054

Author

Jorge Rodríguez Vignoli is a research assistant at the Latin American and Caribbean Demographic Centre (CELADE)-Population Division of the Economic Commission for Latin America and the Caribbean (ECLAC). Email: jorge.rodriguez@cepal.org. 


\section{Introduction ${ }^{1}$}

Urbanization is part of the long-term structural processes that interact to generate economic and social modernization and cultural modernity. A few years ago, urbanization reached a milestone, when the global urban population passed $50 \%$ of the total. All existing projections suggest that this percentage will continue to rise and will likely follow a logistic trajectory, on the assumption that a proportion of the population will remain in rural areas, either because of individual preference or because of economic and social needs.

Today, $80 \%$ of the Latin American and Caribbean population lives in urban areas (United Nations, 2015). This being so, the most frequent kind of internal migration is almost certainly between urban areas. However, inter-city migration has been much less studied than rural-urban migration, which tends to remain the focus, despite its gradual and inevitable depletion. Accordingly, a first objective of this work is to provide a quantitative approach to migration flows between categories and nodes of the human settlements system, with an emphasis on inter-city migration. A second objective is to show that internal migration - especially between cities - has important effects on human settlements and on cities in particular. The analysis will focus on a small fraction of those effects; specifically, the impact of migration on the sex, age and educational structure of settlements.

Following this introduction is a section presenting the main research ideas and the links between them. Next comes a methodological section, which defines the concepts used and lists and discusses the sources, procedures and indicators employed. This is followed by the results, concerning first the magnitude of migration between cities and settlements and later the effect of migration on the composition of the population in cities and settlements. Lastly, the results are discussed, ordering the main conclusions by the three hierarchical levels of the human settlements system: large, mediumsized and small cities (also includes a residual category, called "rest", which groups all the municipalities which do not have cities).

\section{Urbanization, city systems, concentration and internal migration}

Urbanization can be based on very different city systems: from a single metropolis - that is, a highly concentrated system, or a primate system in the technical jargon, such as a city-State or a country with a single large city that coexists with the rest of the rural territory - to a myriad of cities of different sizes. The diversity of levels of primacy in specific city systems suggests that a broad and complex range of factors are involved in determining this, as well as idiosyncratic conditions (Pacione, 2009; Fujita and Krugman, 2004; Hall, 1996; Romero, 1976). The bulk of the literature suggests that primate systems tend to be dysfunctional for development (Williamson, 1965; Henderson, 2003; Atienza and Aroca, 2012).

Homeostatic or self-regulating visions of society - whether neoclassical in economics, functionalist or systems theory in sociology or evolutionist in development theory- assume that the forces of deconcentration will ultimately prevail and large cities will lose economic power and pull, such that the primacy indexes of city systems will fall (Cunha and Rodríguez, 2009; World Bank, 2009; Fujita and

\footnotetext{
1 The author would like to thank Daniela González, Research Assistant with CELADE-Population Division of ECLAC, for her assistance in the definition of cities and obtaining socioeconomic indicators on them, and Mario Acuña, Luis Rodríguez and David Candia, consultants with CELADE-Population Division of ECLAC, for their help with data processing. The author is also grateful for the comments of two anonymous referees, which helped to improve the article. Any remaining limitations and errors in the text are entirely the author's own.
} 
Krugman, 2004; Henderson, 2003; Cuervo and González, 1997). Evolutionist approaches also propose deconcentration as a - sometimes final - "counter-urbanization" phase. During this phase, growth and migratory pull shifts from the large cities to medium-sized and small ones, in response to the problems that emerge in the large cities (Pacione, 2009; Geyer and Kontuly, 1993; Berg and others, 1982).

Counter-urbanization and, in general, the hypothesis of an inevitable tendency towards the deconcentration of city systems, have been questioned from various perspectives. One of these is "concentrated deconcentration" (Cunha, 2015; ECLAC, 2012; Cunha and Rodríguez, 2009; Villa and Rodríguez, 1997) or the formation of city-regions (Sassen, 2007), whereby metropolitan areas lose demographic (and economic) gravitational pull as their surroundings, especially nearby cities, gain pull of their own; here, what is actually occurring is the expansion of the geographical scale of the metropolitan area. Counter-urbanization is also questioned from a number of evolutionist perspectives, in particular those which include a final stage of reconcentration or metropolitan resurgence (Cunha, 2015; Pacione, 2009). The structuralist approach developed by the Economic commission for Latin America and the Caribbean (ECLAC) adopts mainly the centre-periphery perspective, which is normally associated with mechanisms and processes that exacerbate or at least tend to reproduce concentration, asymmetry and inequality. At the global level, peripheries may be characterized as follows: they are productive structures that have few dynamic activities, being associated instead with exports of primary or semiprocessed goods with few linkages, or subsistence activities; they are structurally highly uneven in terms of productivity levels between sectors and firm sizes, which leads to acute labour segmentation and steep income inequalities; and they are slow to absorb technical progress, which tends to be concentrated in just a few sectors of the economy. These features tend to be reproduced within countries, except that there is a centre or centres formed by the large cities, and the periphery consists of the rest of the human settlements system. The structuralist approach is not limited to the effects of centrifugal and centripetal forces, but also underlines the cumulative role of history in the formation of the Latin American States and economies of today. In this regard, it highlights the role played by the social and political-institutional matrix in the concentration of the population since the Spanish conquest (or even before). The difference between diversified production structures like those of the metropolis, and structures that are specialized - particularly in raw materials - like those of the rest of the country or the periphery, will in principle fuel inequalities and concentration. To this is added the effects of value chains, which transfer resources from the periphery to the centre, as well as selective migration, which also favours the centre. Be this as it may, these basically concentrating mechanisms can be offset by public policies or they can be disabled by structural shifts in the economy. Accordingly, the structuralist approach does not necessarily project an inevitable rise in concentration in the large cities either (ECLAC, 2015, pp. 18-24).

Migration is key dimension of the discussion on the trend and future of demographic and economic concentration in large cities and their influence on national development. In the case of migration between cities, the differentiation between origin and destination, so evident in the case of rural-urban migration, is blurred given that both are urban. Although there are socioeconomic and other disparities between cities that prompt people's decisions to migrate, the differences tend to be smaller and more subtle, nuanced and complex than the distinction between the countryside and the city. The classic models of rural-urban migration based on labour market differentials -i.e. basically disparities in unemployment and income - are thus somewhat limited in their ability to explain inter-city migration (Rodríguez and Busso, 2009; Aroca, 2004; Brown, 1991; Martine, 1979; Villa and Alberts, 1980), as they tend to disregard the factors related to area of residence, culture, education, living standards and cost of living that appear to motivate decisions to move from one city to another and can sometimes be dissociated from levels and trajectories of income and employment. 
Consequently, the petering out of migration from the countryside and the more complex and diverse fabric of the city system may be changing the direction of migratory flows. It may also be changing the traditional effects of internal migration on the composition of the population, which in Latin America was broadly to feminize and rejuvenate ${ }^{2}$ large cities, as well as to reduce their education level, and to masculinize and age small cities and rural areas (Elizaga, 1970; Camisa, 1972; Elizaga and Macisco, 1975; Alberts, 1977; Rodríguez, 2013a and 2013b).

This work proceeds, first, with an updated quantification of migration between categories of cities and settlements. Second, it gives an initial description of relations as they exist today between demographic size, living standards and migratory pull of cities and settlements. Lastly, it evaluates empirically the effects of migration on composition by age, sex and level of education of the population in cities and settlements.

\section{Methodological framework}

The results presented in this article come from the processing of census databases from 10 countries of the region -the Bolivarian Republic of Venezuela, Brazil, Costa Rica, the Dominican Republic, Ecuador, Honduras, Mexico, Panama, the Plurinational State of Bolivia and Uruguay - two of them (Brazil and Mexico) the most populous in Latin America. The census data were used to build matrices of origin and destination of recent migration between cities, understood as all localities and urban and metropolitan agglomerations of at least 20,000 inhabitants. In order to capture the whole of the human settlements system in the calculations and the analysis, the matrices include a residual category grouping all those municipalities without cities.

The geographical definition of cities comes from the spatial distribution and urbanization in Latin America and the Caribbean (DEPUALC) database (www.cepal.org/celade/depualc/). This recently updated database uses an urban areas and conglomerates approach to avoid limiting cities strictly to the urban sprawl. In general, the geographical definition of cities in DEPUALC is based on the urban area of the minor administrative division (MIAD) ${ }^{3}$ where the city is located or of the MIADs that contain or make up the city (in the case of cities which exceed the boundaries of a single MIAD). All cities which meet the minimum size requirement (i.e. 20,000 inhabitants or more) form part of the list of cities.

MIADs are used to create the origin-destination matrices because they offer the most disaggregated geographical scale at which migration is captured in most countries. The questions about the MIAD of current residence and the MIAD of residence five years earlier are used to build up all the cities with 20,000 or more inhabitants in each country, either as complete MIADs (the MIAD where the city is located, in the case that the city does not exceed it), or as groupings of MIADs (those which make up the city or across which the city extends). These new entities corresponding to cities are then used as origins and destinations in the respective destinations, generating inter-city migration matrices which yield all the standard indicators on volume and intensity of migration.

The matrices include a column entitled "rest", which groups all the MIADs which do not have a city, from which estimates can be obtained on net migration exchange between the cities system and the rest of the settlements in the country. In other words, the "rest" category permits an innovative approach

\footnotetext{
2 "Rejuvenate" is not used in the demographic sense of increasing the child population, but in the literal sense of increasing the proportion of young people, defined as the population aged between 15 and 29 years.

3 A minor administrative division (MIAD) can refer to a municipality, delegation, department, among others, depending on the country.
} 
to directly estimating rural-urban migration. The threshold for defining rural is quite strict in this case, since these are MIADs which do not have or do not form part of a city of at least 20,000 inhabitants. Even so, this category includes some MIADs whose population is entirely rural and dispersed, as well as others that have small urban localities or areas that are still rural but in the early or intermediate stages of suburbanization.

The migration matrices by city - of some 800 by 800 in countries such as Brazil - are available in the Database on Internal Migration in Latin America and the Caribbean (MIALC) (www.cepal.org/celade/ migracion/migracion_interna/). In this article, in order to conduct a standardized analysis and for obvious reasons of space, the results are presented by cities grouped by population size. The groupings are: ${ }^{4}$ (i) 1,000,000 inhabitants or more (large cities); (ii) between 500,000 and 999,999 inhabitants (upperintermediate cities); (iii) between 10,000 and 499,999 inhabitants (lower-intermediate cities); (iv) between 50,000 and 99,999 inhabitants (upper-small cities); (v) between 20,000 and 49,999 inhabitants (lowersmall cities); (vi) less than 20,000 inhabitants ("special" lower-small category)5, and (vii) the rest.

The calculations derived from the matrices are: (i) population resident at the date of the census; (ii) population resident five years before the census; (iii) non-migrants; (iv) immigrants; (v) emigrants; (vi) net migration; (vii) gross migration; (viii) in-migration rate; (ix) out-migration rate; and (x) net migration rate. ${ }^{6}$ These data are accompanied by the proportion of cities with positive balances or rates; otherwise the overview of the migratory situation of the human settlements system could derive solely from the total, which could be shaped mainly by the main city or cities or by extreme cases.

To estimate the effect of internal migration on the composition of the population, the procedure developed by the Latin American and Caribbean Demographic Centre (CELADE)-Population Division of ECLAC is used (Rodríguez, 2013a and 2013b; CEPAL, 2012; Rodríguez and Busso, 2009). The procedure is based on comparison of the marginals of the flow indicator matrix (from the migration matrix five years before the census), one of which is the value of the attribute at the time of the census (factual value), i.e. with migration, and the other, the attribute as it would be if migration had not occurred (counterfactual value). The difference between the two is the effect (net and exclusive) of migration on the attribute. The ratio between the effect and counterfactual is the relative effect of migration on the composition of the population in terms of that particular attribute.

This procedure was used to estimate the effect of migration on the structure by sex, age and education of the cities of the region, grouped into the size categories mentioned, including the category "rest", which assimilates the rural or semirural sphere. To calculate the effect on population structure by sex, the masculinity ratio was used, that is, the ratio of men to women; in the case of age structure, the percentage represented by selected age groups - 5-14 years, 15-29 years, 30-44 years, 45-59 years and 60 years or over - within the total population (strictly speaking, the population including the migration

\footnotetext{
4 Except in the case of the term "large cities", used to refer to cities whose size makes them in fact large in any national context, the use of terms such as "intermediate" or "small" is exclusively pragmatic. Whether a city is "intermediate" in a given country depends on the city system in that country. Cities that are intermediate in Brazil or Mexico would be the second largest in Uruguay and Panama, for example, by number of inhabitants. Although the DEPUALC and MIALC databases permit a definition of intermediate cities associated with the characteristics of the city system in each country, the author of this work has opted for a common criterion for all the countries in order to standardize the analysis, even though this may involve the risk of grouping different cases together.

5 The population corresponding to the category "less than 20,000 inhabitants" is a derivation of the method and not a value for all the cities of less than 20,000 inhabitants. The category is those which had less than 20,000 inhabitants in 2010 but not in 2000 and therefore do not fall within the 20,000-49,999 group in 2000, and have to be added to the "rest" category, rather than being treated as a special case. There are exceptional cases of this sort in 2010 , corresponding to cities which that year exceeded 20,000 inhabitants in the matrix but not in DEPUALC. This category is marginal and can be added to the "rest" category in the corresponding years.

6 For further details on the calculation of these indicators, see Rodríguez (2013a and 2011), Welti (1997) and Villa (1991).
} 
matrix, which excludes children under age 5 and recently international immigrants); and in the case of education, average years of study of the population aged 25 years and over and the group aged 45-59 years, to try to control for the distortion generated by the age structure. These effects can, of course, be broken down into the impacts of in-migration and out-migration. The first is obtained as the difference between the factual value and the value for non-immigrants for each place. The second is obtained as the difference between the value for non-migrants and the counter-factual value for each place.

\section{Results and analysis}

\section{City systems and internal migration: continuity and change in migratory pull and the general growth effect}

The results presented confirm the findings of Rodríguez (2011), insofar as the lower bands of the city system show net loss of population, the intermediate bands are tending to pull in population and the upper bands are still exerting pull as well (see figure 1). The fact that the lower bands of the city system are losing population leads a situation that is surprising and even paradoxical, given the welldocumented march of urbanization in the past few decades: because small cities far outnumber larger ones, the fact that they are losing population means that most cities are showing net out-migration (see figure 2).

\section{Figure 1}

Latin America and the Caribbean (selected countries): net internal migration rate by segment of the human settlements system grouped by population size, population aged 5 years and over ${ }^{\mathrm{a}}$

(Number of persons per 1,000)

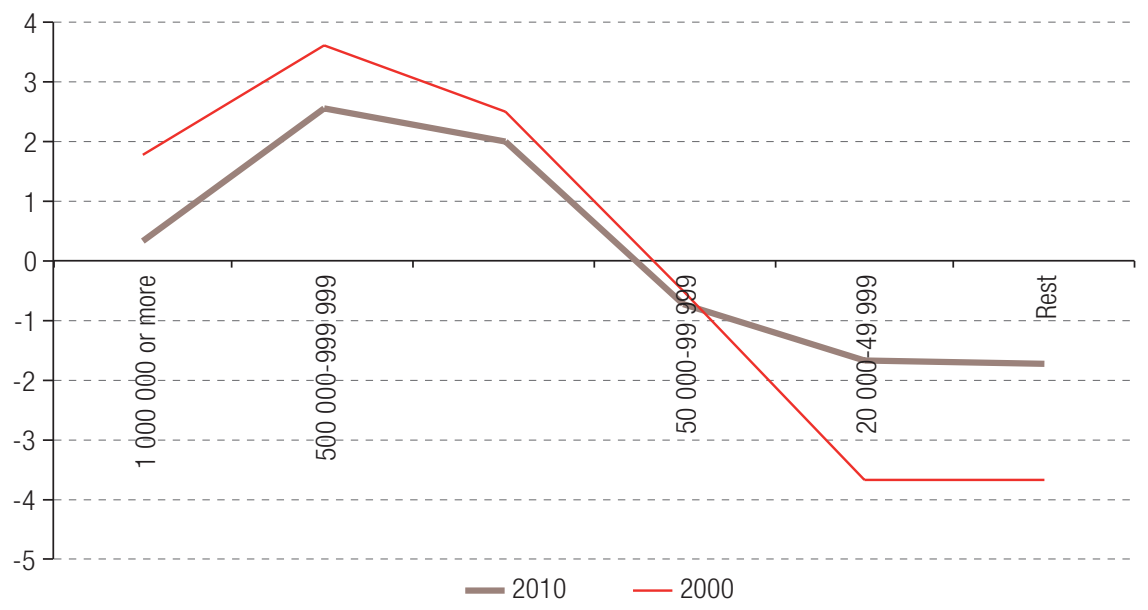

Source: Prepared by the author.

Note: Excludes the category "less than 20,000 inhabitants".

a Includes 10 countries with censuses and information available from the 2010 census round (Bolivarian Republic of Venezuela (2011), Brazil (2010), Costa Rica (2011), Dominican Republic (2010), Ecuador (2010), Honduras (2013), Mexico (2010), Panama (2010), Plurinational State of Bolivia (2012) and Uruguay (2011)) and eight from the 2000 census round (Bolivarian Republic of Venezuela (2001), Brazil (2000), Costa Rica (2000), Dominican Republic (2002), Ecuador (2001), Honduras (2001), Mexico (2000) and Panama (2000)). 
Figure 2

Latin America and the Caribbean (selected countries): cities by net migration sign, by range of population size of the citya

(Number of cities)

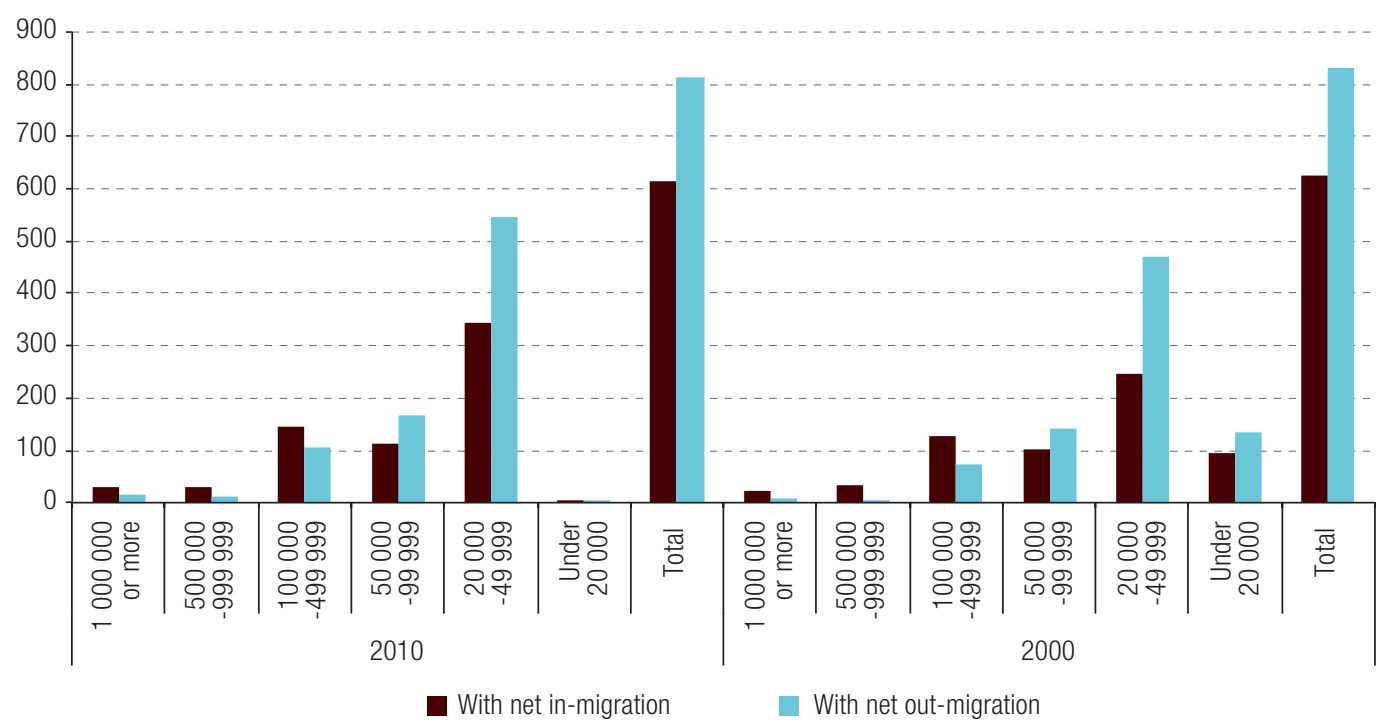

Source:Prepared by the author, on the basis of information from the Database on Internal Migration in Latin America and the Caribbean (MIALC).

Note: The number of cities in 2000 includes almost 300 localities which were not cities in that year's census, but had become cities by the census of 2010 . Their inclusion facilitates the diachronic comparison and explains the very similar number of cities at the two points in time.

a Includes 10 countries with censuses and information available from the 2010 census round (Bolivarian Republic of Venezuela (2011), Brazil (2010), Costa Rica (2011), Dominican Republic (2010), Ecuador (2010), Honduras (2013), Mexico (2010), Panama (2010), Plurinational State of Bolivia (2012) and Uruguay (2011)) and eight from the 2000 census round (Bolivarian Republic of Venezuela (2001), Brazil (2000), Costa Rica (2000), Dominican Republic (2002), Ecuador (2001), Honduras (2001), Mexico (2000) and Panama (2000)).

Table 1 offers another way to approach the direct estimation of rural-urban migration, by calculating the migratory balance of the category termed "rest" - bearing in mind the caveats set forth in the methodological framework, particularly with respect to the heterogeneity within that category. The "rest" category is systematically losing population, which suggests that rural-urban migration is continuing and showing no signs of reversal, although it is slowing.

It can also be seen in table 1 that most migrants are urban-urban. Of the 14.4 million migrants registered in the 2010 census round, 11.2 million (78\%) were immigrants into cities and 10.6 million (73.5\%) were emigrants from cities, which means that three of every four migrants moved between cities. This percentage is around $80 \%$ in the case of the intra-category flows shown in the second component of table 1, and could be even higher in the case of intra-metropolitan migration - not included in the calculations presented here - which is substantial in the more urbanized and "metropolized" countries. The calculations also omit intrarural migration (which occurs within the "rest" segment), which precludes obtaining a measure of rural-rural flows.

Also striking in table 1 is that the large cities show quite a small migratory balance (a rate of barely 0.3 per 1,000 according to the 2010 census round), much lower than in the 2000 census round. Notably, inspection of the matrices of migration between cities - available in the MIALC database - shows that this group is internally diverse, since all the megacities or supercities (cities of 10 million or more inhabitants) show net out-migration, while most of the other large cities still show net in-migration. Medium-sized cities were the most attractive during the period examined, with a slightly falling net in-migration rate between the two census rounds. In any case, these are still moderate rates (of around 3 per 1,000), far short of the annual rates of upwards of 20 per 1,000 that were common until the 1980s (Alberts, 1977). 


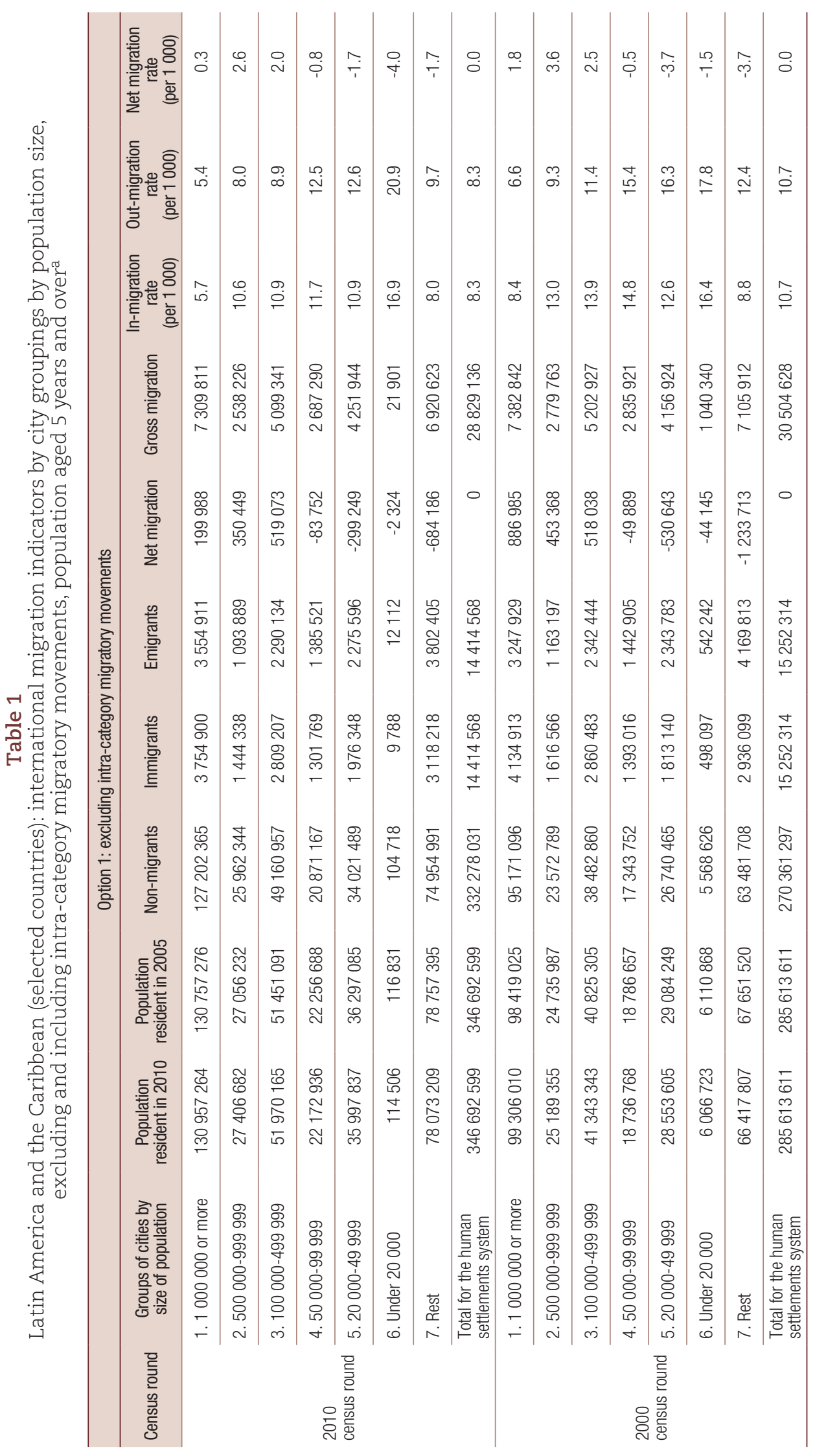




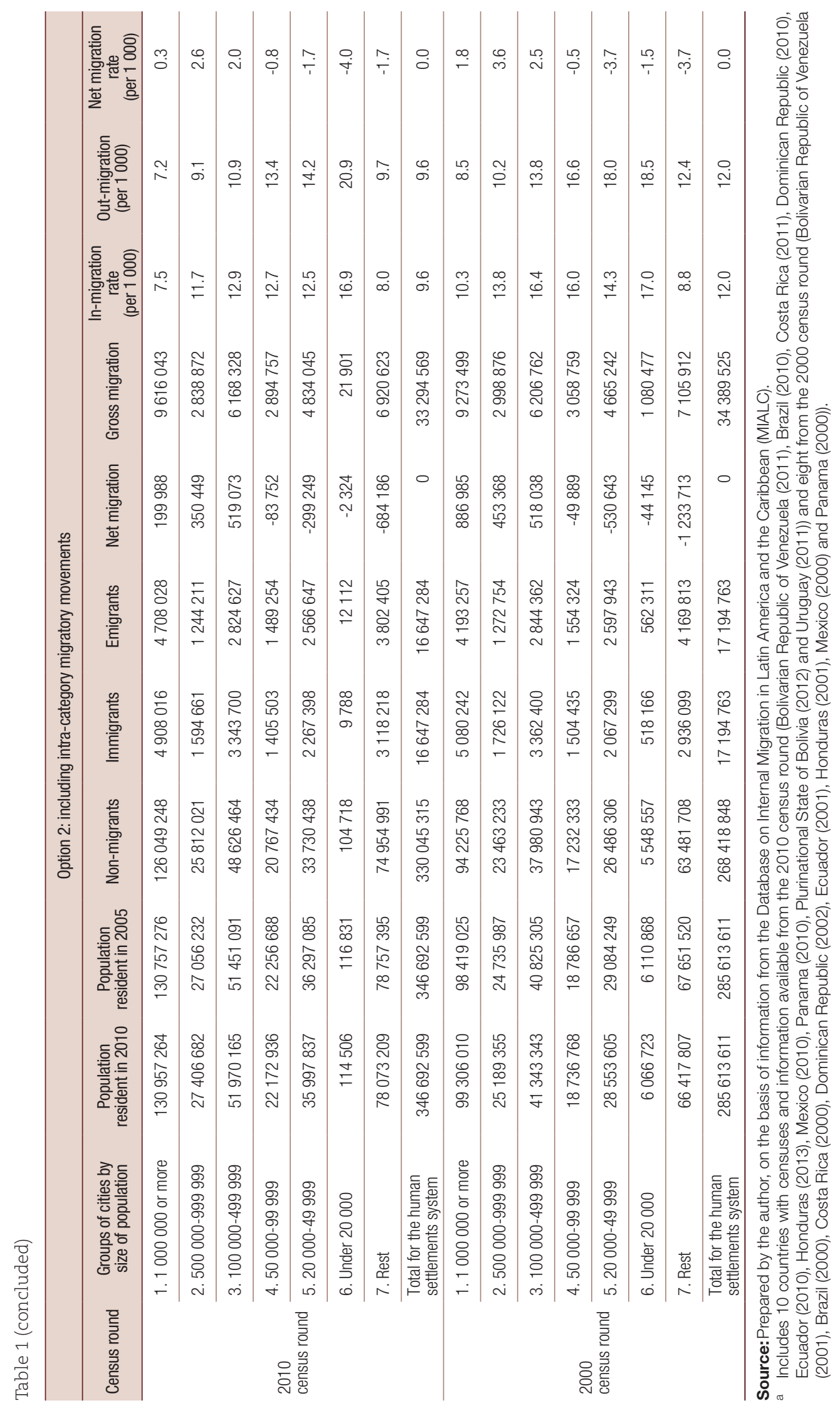


The combination of data provided in table 1 suggests that internal migration is tending to produce a certain deconcentration of the population, although this process is limited to the medium-sized cities, extending to some extent to smaller cities but less to the rural sphere.

Comparison between the two components of table 1 allows another discussion, given that the difference between the two corresponds, as explained in the methodological section, to the amount of migration between cities in the same category. This migration alters the quantity of immigrants and emigrants in each category of city and their respective rates, but not the net migration in the category - precisely because it is intra-category migration, which does not imply exchanges with other categories - so this value is identical in the two components of the table. ${ }^{7}$ The results (see figure 3) show that migration within each category of the city system tended to increase in the last inter-census period, at least in absolute terms, which reflects a growing horizontal migratory exchange that contrasts with the overall reduction in internal migration shown in previous figures and studies (ECLAC, 2012; Bell and Salut, 2009). This warrants further research.

Figure 3

Latin America and the Caribbean (selected countries): number of intra-category migrants in the city system, population aged 5 years and over ${ }^{a}$ (Millions of persons)

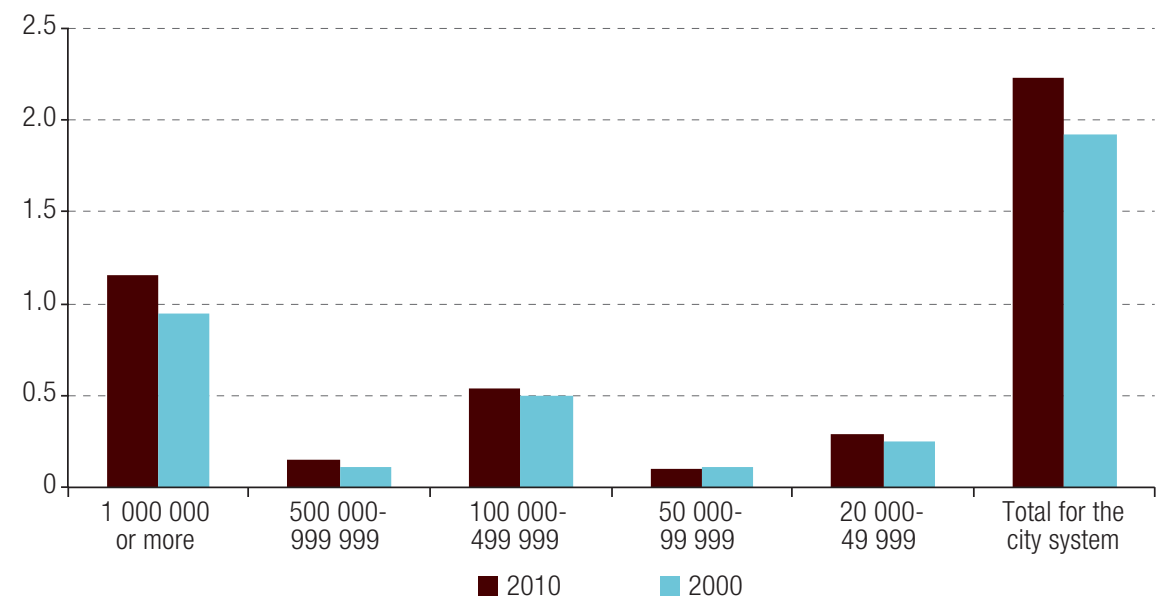

Source: Prepared by the author, on the basis of information from the Database on Internal Migration in Latin America and the Caribbean (MIALC).

Note: Excludes the category "less than 20,000 inhabitants".

a Includes 10 countries with censuses and information available from the 2010 census round (Bolivarian Republic of Venezuela (2011), Brazil (2010), Costa Rica (2011), Dominican Republic (2010), Ecuador (2010), Honduras (2013), Mexico (2010), Panama (2010), Plurinational State of Bolivia (2012) and Uruguay (2011)) and eight from the 2000 census round (Bolivarian Republic of Venezuela (2001), Brazil (2000), Costa Rica (2000), Dominican Republic (2002), Ecuador (2001), Honduras (2001), Mexico (2000) and Panama (2000)).

Unlike what has been observed in the case of rural-urban migration, which is explained by natural structural reasons, such as persistent sharp inequalities between urban and rural areas - corroborated both in figure 4, which shows the enormous, stubborn and even growing urban-rural poverty gap in Latin America, and in recent publications (Srinivasan and Rodríguez, 2016) -, in the case of cities grouped by population size, the inequalities are less systematic (see table 2).

\footnotetext{
7 Unfortunately, migration in the "rest" category is not registered, because is it a residual category treated as a unit without distinguishing one locality (municipality, strictly speaking) from another.
} 


\section{Figure 4}

Latin America and the Caribbean: poverty by area of residence and differential between rural and urban areas, 1980-2013

(Percentages and rural/urban ratio)

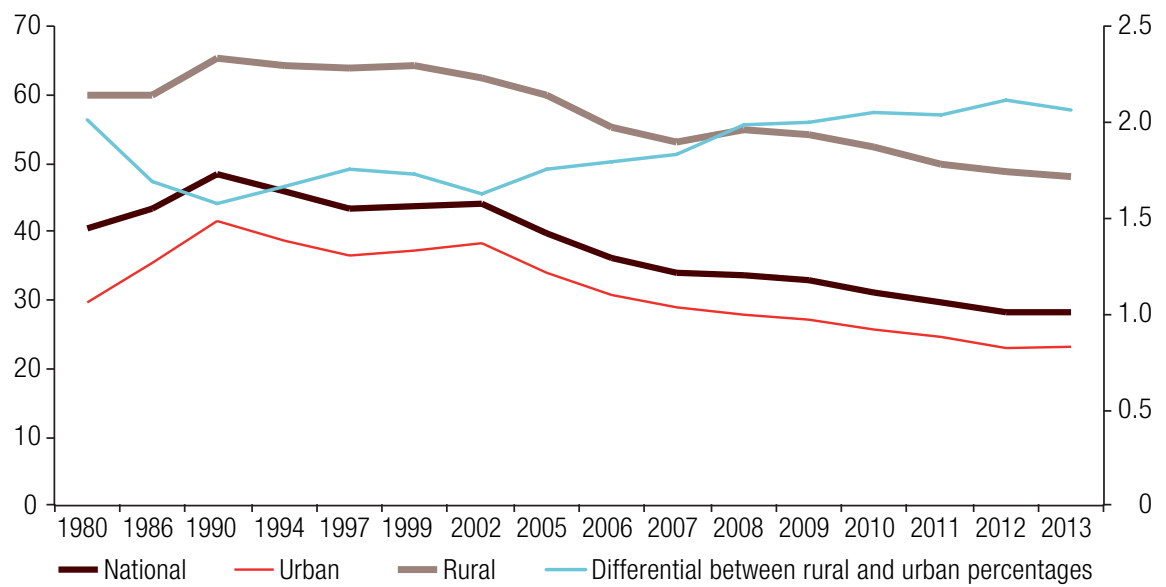

Source:Economic Commission for Latin America and the Caribbean (ECLAC), CEPALSTAT, on the basis of special tabulations from household surveys of the respective countries, 2015.

Table 2

Latin America and the Caribbean (6 countries): indicators of living conditions (Millennium Development Goals) by city groupings by population size ${ }^{a}$

\begin{tabular}{|c|c|c|c|c|c|c|c|c|c|c|}
\hline \multirow{2}{*}{ Cities } & \multicolumn{3}{|c|}{ Average years of schooling } & \multirow{2}{*}{$\begin{array}{l}\text { Net } \\
\text { enrolment } \\
\text { in primary } \\
\text { school }\end{array}$} & \multirow{2}{*}{$\begin{array}{c}\text { Primary } \\
\text { education } \\
\text { completion } \\
\text { rate }^{b}\end{array}$} & \multirow{2}{*}{$\begin{array}{l}\text { Literacy } \\
\text { rate }\end{array}$} & \multicolumn{3}{|c|}{ Male/female ratio } & \multirow{2}{*}{$\begin{array}{l}\text { Literacy } \\
\text { rate }\end{array}$} \\
\hline & Both sexes & Men & Women & & & & $\begin{array}{c}\text { Primary } \\
\text { education }\end{array}$ & $\begin{array}{c}\text { Primary } \\
\text { education }\end{array}$ & $\begin{array}{c}\text { Tertiary } \\
\text { education }\end{array}$ & \\
\hline 1000000 or more & 10.0 & 10.3 & 9.7 & 80.6 & 98.3 & 98.9 & 1.02 & 0.99 & 0.94 & 98.3 \\
\hline 500 000-999 999 & 10.2 & 10.5 & 9.9 & 74.6 & 96.8 & 98.7 & 1.02 & 0.97 & 0.91 & 97.0 \\
\hline 100 000-499 999 & 9.7 & 9.8 & 9.5 & 82.5 & 97.2 & 98.8 & 1.02 & 0.99 & 0.88 & 97.2 \\
\hline 50 000-99 999 & 8.6 & 8.9 & 8.3 & 78.2 & 97.8 & 98.4 & 1.02 & 0.98 & 0.94 & 96.6 \\
\hline $20000-49999$ & 8.2 & 8.5 & 8.0 & 78.7 & 96.5 & 98.0 & 1.02 & 0.96 & 0.90 & 96.1 \\
\hline Cities & $\begin{array}{l}\text { Proportion } \\
\text { of the } \\
\text { population } \\
\text { with access } \\
\text { to drinking } \\
\text { water }^{b}\end{array}$ & $\begin{array}{l}\text { Proportion } \\
\text { of the } \\
\text { population } \\
\text { with } \\
\text { access to } \\
\text { sanitation }\end{array}$ & $\begin{array}{l}\text { Proportion } \\
\text { of the } \\
\text { population } \\
\text { with } \\
\text { access to } \\
\text { electricity }\end{array}$ & $\begin{array}{l}\text { Telephone } \\
\text { in the } \\
\text { household }\end{array}$ & $\begin{array}{l}\text { Mobile } \\
\text { telephone } \\
\text { in the } \\
\text { household }\end{array}$ & $\begin{array}{l}\text { Computer } \\
\text { in the } \\
\text { household }\end{array}$ & $\begin{array}{l}\text { Internet } \\
\text { in the } \\
\text { household }\end{array}$ & $\begin{array}{l}\text { Masculinity } \\
\text { ratio }\end{array}$ & $\begin{array}{l}\text { Youth } \\
\text { ratio }\end{array}$ & $\begin{array}{l}\text { Old-age } \\
\text { ratio }\end{array}$ \\
\hline 1000000 or more & 84.6 & 96.2 & 99.5 & 64.4 & 75.8 & 43.9 & 31.9 & 94.2 & 41.8 & 14.6 \\
\hline 500 000-999 999 & 93.4 & 79.8 & 99.0 & 54.1 & 82.7 & 42.8 & 33.4 & 93.7 & 41.7 & 13.9 \\
\hline 100 000-499999 & 83.7 & 94.9 & 90.2 & 49.6 & 78.4 & 38.7 & 25.9 & 93.8 & 44.8 & 14.3 \\
\hline 50 000-99 999 & 83.9 & 84.5 & 93.0 & 41.2 & 69.6 & 29.9 & 18.6 & 94.3 & 49.1 & 14.0 \\
\hline $20000-49999$ & 82.6 & 79.6 & 93.0 & 36.9 & 67.2 & 25.7 & 15.4 & 94.4 & 50.3 & 15.4 \\
\hline
\end{tabular}

Source: Prepared by the author, on the basis of information from the database Spatial distribution and urbanization in Latin America and the Caribbean (DEPUALC).

a Includes six countries with census information available from the 2010 census round: Costa Rica, Dominican Republic, Ecuador, Mexico, Plurinational State of Bolivia and Uruguay.

b More details on the indicators can be found in the DEPUALC database. 
The main pattern observed is that small cities generally tend to have lower standards of living, which pushes the population to emigrate towards the higher levels of the city system, certainly not towards the rural sphere which, as shown in figure 4, has much lower indicators.

\section{City systems and internal migration: continuity and change in the migratory pull and growth effect for particular population subgroups}

The tables below present the best known traditional synthetic indicators of migration - migratory balance and migration rates - for the two variables that define the demographic structure of the population: sex and age. In the case of migratory balance, since these are absolute numbers, the table is a summary of the regional totals for each category of the human settlements system, obtained from the sum of the migratory balances of all the cities included in the analysis, so it offers a sort of regional migratory balance. To this are added indicators of the quantity and percentage of the cities of net in-migration and out-migration, giving a first picture of the diversity behind the regional totals.

The migration rates, conversely, are shown disaggregated by country, because: (i) they are relative figures so can be used for comparison between countries, and (ii) this makes it possible to control for the dominant effect exerted by Brazil and Mexico on the regional averages, owing to their demographic weight and number of cities. The rates are disaggregated by sex only, since disaggregations by age would take up too much space (although these are available upon request). The presentation and analysis of these indicators are also a preamble to the following section, which analyses the results of an innovative procedure developed by CELADE-Population Division of ECLAC to estimate the effect of internal migration on the sex and age composition of the different categories of cities, as well as their educational level.

Tables 3 and 4 show that large cities are still the most attractive for women, and that the lower band of the human settlements system, especially rural areas, expels more women than men. Although the migratory balance is falling for both sexes, in the case of men this is leading to migratory equilibrium, whereas for women the balance is still positive by around 200,000 migrants. By contrast, the migratory balance of medium-sized cities shows no great difference by sex, quantity or trend, although the balance is slightly larger for women. The migratory balances of the lower part of the human settlements system maintain their traditional tendency to expel both sexes, although this is clearly more marked in the case of women, in whose case these areas show a negative balance of over 400,000 migrants.

With regard to age, there is a pattern that stands out for its persistence, universality and magnitude. Young people (aged 15-29 years) are strongly attracted to large cities and, conversely, leave small cities and rural areas (represented by the category "rest" in table 5) in large numbers. This behaviour is very marked, as table 5 shows that in both censuses large cities lost population from all the other age groups, but the gain in the youth population offsets this loss to such an extent that the large cities show a positive migratory balance at the regional level. Although the youth group has been not unaffected by the generalized fall in the migratory balance of the large cities, in this case the reduction is nowhere near a plunge.

Disaggregating by age also reveals a new -and, to a point, unexpected - trend. In the 2010 census round, the "rest" category showed positive balances in three age groups - under 15 years, 30-44 years and 45-59 years - which marks a departure from the observations of the 2000 census round. In the classic models of migration by age (Moultrie and others, 2013; Rogers and Castro, 1982), this combination is usually associated with what is termed family migration, i.e. families of adults and children migrating together. 


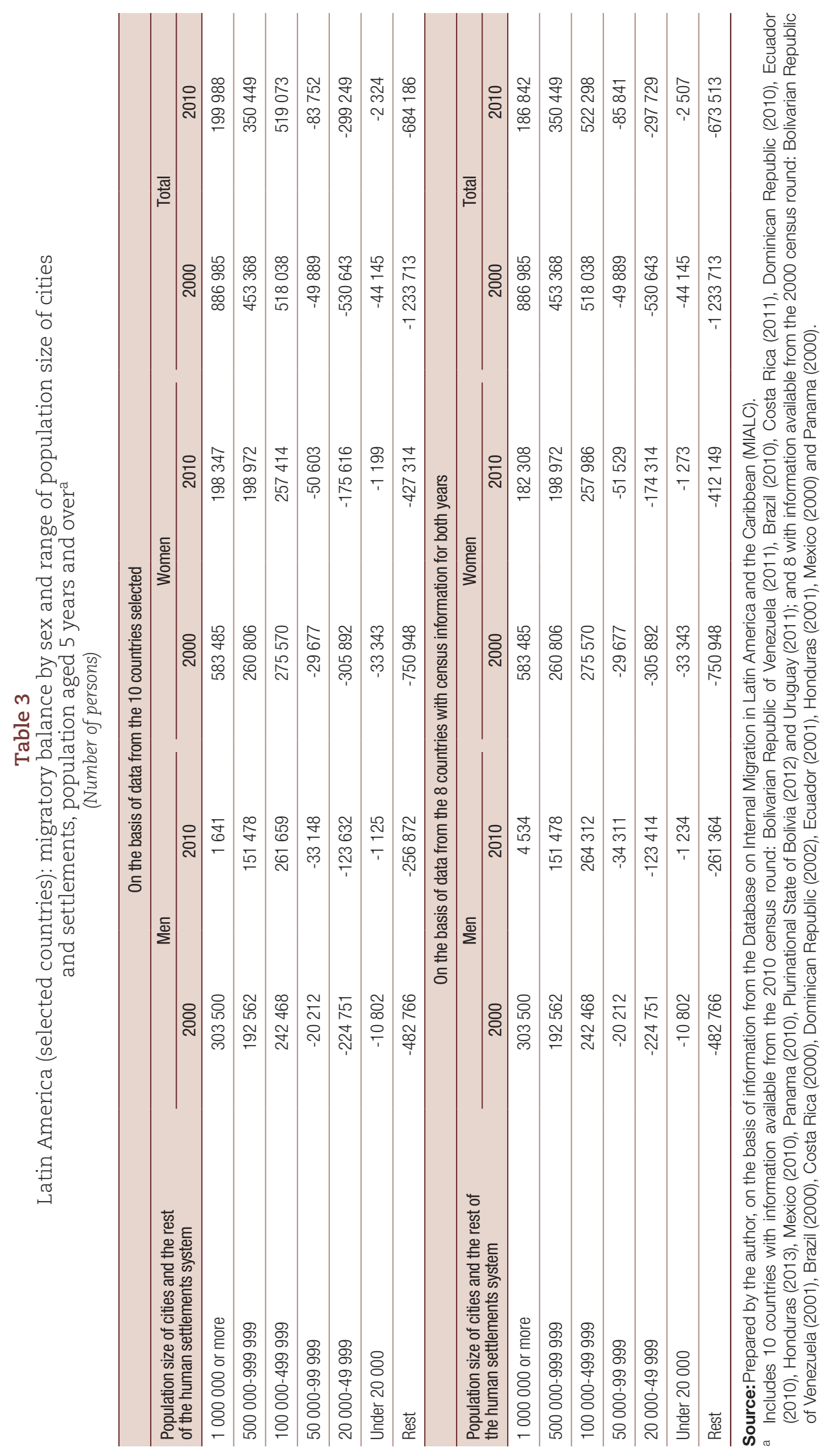




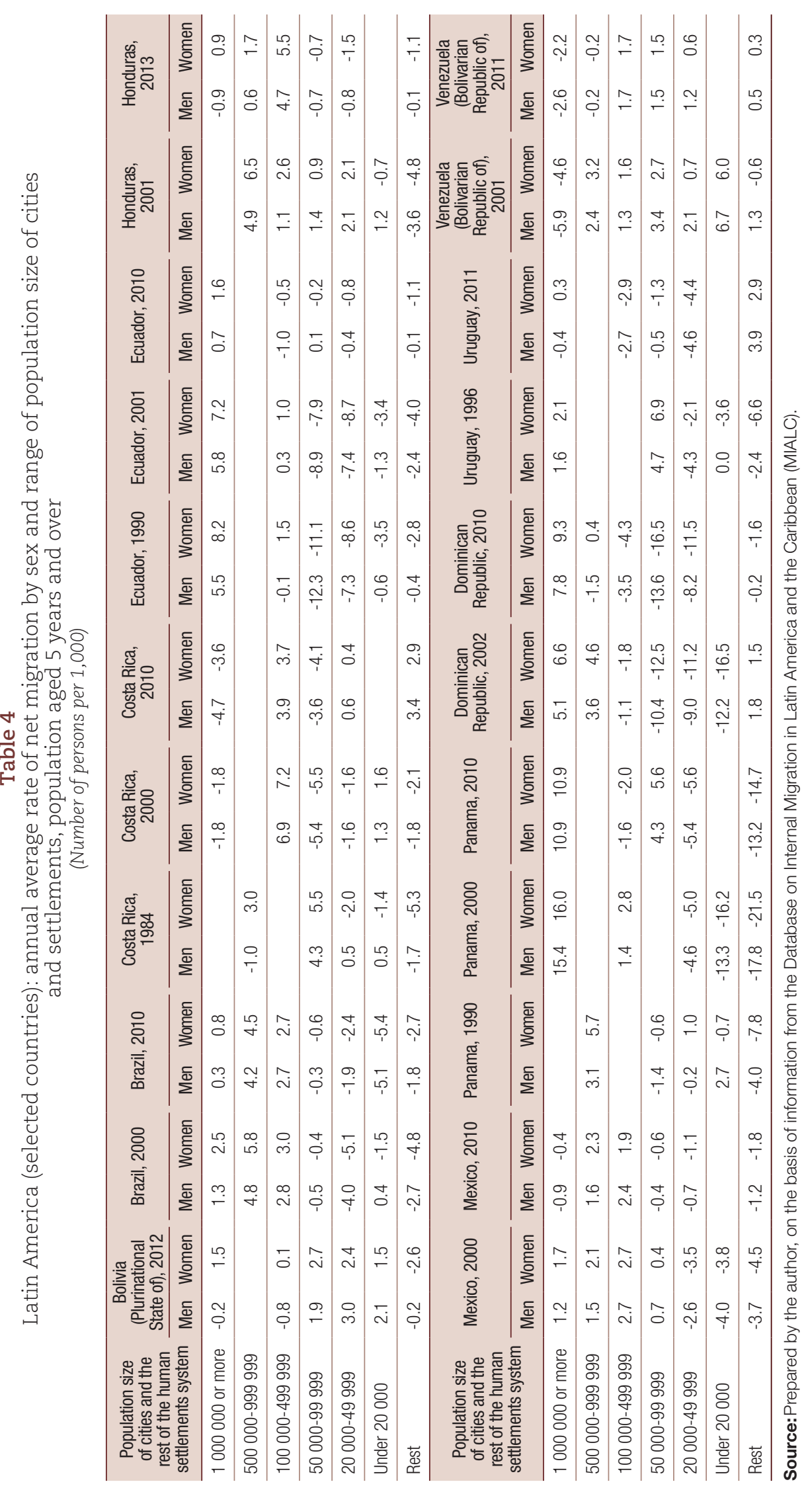




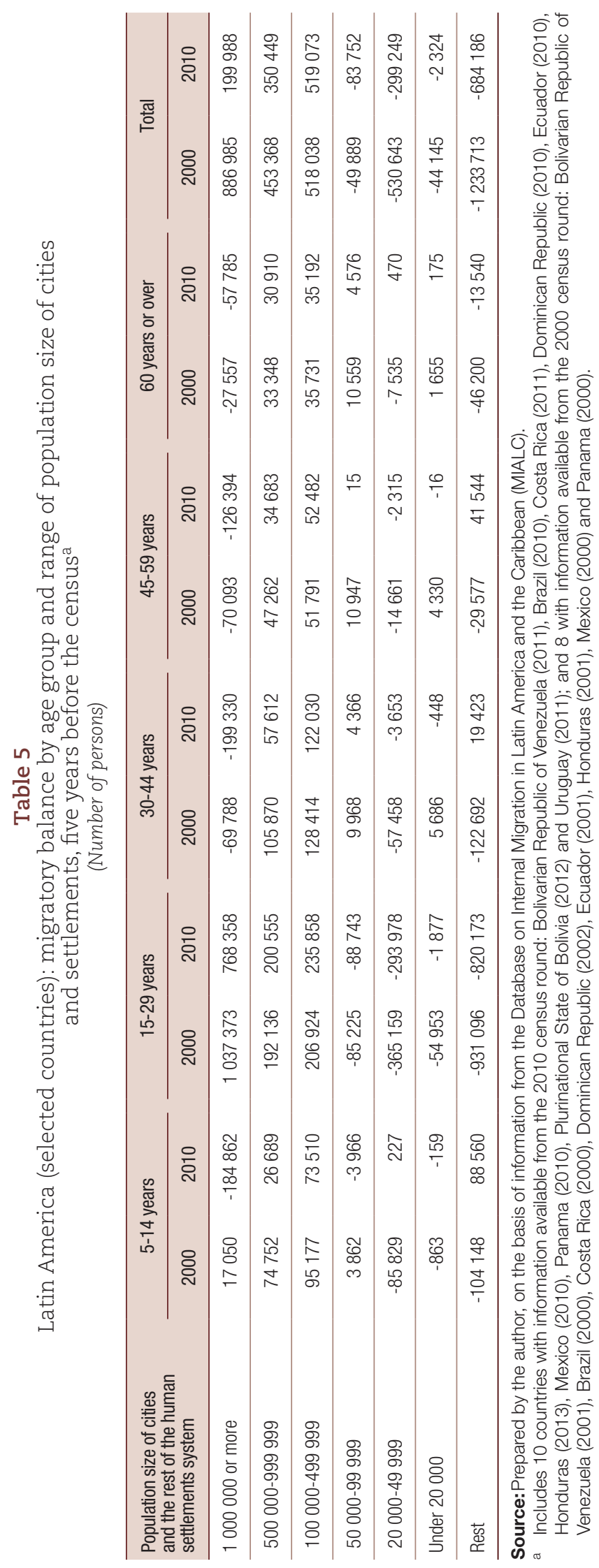




\section{Net and exclusive effects of internal migration on population structure by sex and age}

The main results of the application of the innovative procedure developed by CELADE-Population Division of ECLAC for estimating the effect of internal migration on the composition of the population may be summarized as follows:

(i) In almost all the countries, internal migration continues to reduce the masculinity index of large cities, with the exception of a few cities such as San José or Panama City, where this effect has dissipated as net migration rates have converged between the two sexes. In general, this "feminizing" effect has lessened, although with (probably circumstantial) fluctuations in some countries. The strongest feminizing effect is seen in the large cities of Ecuador, between 1985 and 1990 , when migration led to a fall of $1.4 \%$ in the masculinity ratio. Although at first sight this does not appear to be a large figure, in comparative demographic terms it does represent an exceptional shift, because falls of that magnitude in the masculinity ratio of national populations or cities in just five years are normally the result of highly gender-biased mortality events, such as wars. The reverse side of the sharp feminization of the large cities is the continued masculinization of small cities and the rural environment. In some countries, these segments show rises of around $1 \%$ in the masculinity ratio with respect to the counterfactual scenario of no migration in the reference period.

(ii) The "rejuvenating effect" of migration on large cities is fully confirmed. Almost all the countries saw rises of over $1 \%$ in the proportion of youth with respect to the non-migration (counterfactual) scenario in the last five years. This figure exceeded $3 \%$ in several countries and came close to $5 \%$ in the most extreme cases, such as Panama, in the 2000 census round (see table 6). Given the importance of the calculations of this effect, and the possibility of using them to illustrate inputs, results, potentials and limitations of the procedure used, table 6 also shows other results obtained. The first three columns contain the factual, counterfactual and non-migrant values for the percentage of young people. ${ }^{8}$ There is an obvious disparity between the large and medium-sized cities, and the small cities and the "rest", which is particularly pronounced in the Dominican Republic, Ecuador, Honduras, Panama, the Plurinational State of Bolivia and Uruguay, where the difference between the factual value (which includes migration that has actually occurred) between large cities and the "rest" is 2 percentage points in Uruguay and as much as 5 percentage points in the Plurinational State of Bolivia. ${ }^{9}$ In principle, these differences should occur in the opposite direction, because the more advanced stage of the already longstanding and rapid demographic transition in the large cities generates an age structure with a smaller proportion of young people and larger proportion of mature adults and older persons. In this regard, the disparities observed, which cannot be attributed to inertial population dynamics, can only be produced by the cumulative effect of internal migration. The second and third columns show the percentage young people would represent in the absence of internal migration between city categories and the percentage of young people among non-migrants, which are inputs for subsequent calculations. The fourth column shows the absolute difference between the factual and counterfactual values, which is the net and exclusive effect of migration on the percentage of young people. This is referred to as an absolute effect, because it is a subtraction of original values (in this case, percentages). In all the countries, this effect is positive

\footnotetext{
8 It will be recalled that "percentage of young people" refers to the population aged between 15 and 29 years within the total population, and does not include those aged under 5 or recent international migrants.

9 Only the Bolivarian Republic of Venezuela and Costa Rica show differences in the other direction, i.e. a larger percentage of young people elsewhere than in the large cities.
} 
in the case of large cities and negative in the case of small cities and the rest. The greatest effect occurs in Panama, where migration raises the percentage of young people in large cities by 1.2 percentage points and reduces it by 1.6 percentage points in the "rest" category. The fifth column shows the data used for comparative purposes, because these standardize, in the form of a ratio, the absolute effect with respect to the counterfactual value of the attribute. Again, the largest relative effect occurs in Panama, where internal migration raises the percentage of young people in large cities by $4.5 \%$ and lowers it by $5.7 \%$ in the "rest" category. Finally, the last two columns show the absolute effect of in-migration and out-migration, the sum of which gives the total absolute effect. This breakdown is essential to properly interpret the processes underlying the effect of migration on age structure. In fact, the case shown in table 6 is very illustrative in this respect. Why does net migration raise the percentage of young people in cities? Let us take the case of the large cities of the Plurinational State of Bolivia, according to the 2012 census, to follow the arguments with figures. First, young people are more highly represented in the age structure of immigrants than in the age structure of non-migrants, as deduced from comparison between the percentage of young people among non-migrants (33.3\% in the case of Bolivia's large cities according to the 2012 census) and the factual percentage (34.1\% in the same case), which has only two components: the percentage of non-migrants and the percentage of immigrants. Second, emigrants too have an age structure more heavily concentrated in youth than non-migrants, as deduced from comparison between the percentage of young people among non-migrants and the counterfactual percentage (33.9\% in this case), which has only two components: the percentage of non-migrants and the percentage of emigrants. Third, the effect of net migration reflects the fact that the rejuvenating effect of in-migration outweighs the "counter-rejuvenating" effect of out-migration, either because immigrants have an age structure with a larger proportion of young people than emigrants, or because the number of immigrants far exceeds the number of emigrants in this age group. Whatever the case, the procedure estimates each effect precisely; thus, the absolute effect of net migration -a rise of 0.4 percentage points in the youth population - arises from the 0.9 -percentage-point elevating effect of in-migration combined with the 0.4-percentage-point lowering effect of out-migration (the sum of these two effects does not coincide with the respective total, owing to the round of decimals).

(iii) Internal migration tends to reduce, sometimes sharply, the proportion of young people in small cities and in the "rest" category, which in extreme cases falls as much as $8 \%$ with respect to the non-migration (counterfactual) scenario over the past five years. This fall is certainly being caused by the still massive out-migration of young people from these categories of the human settlements system, as shown in table 5 .

(iv) The reverse side of this contraction of the youth segment of the population owing to migration away from small cities and rural areas is the rise in the relative weight of the other age groups, particularly those aged under 15 and over 59 years. So, although migration tends to increase the relative weight of adults aged 30-59 years in the lower bands of the city system, the end result is nevertheless a rise in the dependency ratio, which dilutes and shortens the demographic dividend in these places.

Finally, the effects on education levels are fairly tenuous - or at least not as sharp as the effects on the age structure - and do not have an obvious counterpart like the other two variables. This remains the case after controlling for age. Both in large cities and in small cities and the rest, migration tends to produce a fall in the level of schooling. Only medium-sized cities register positive effects, although very slight ones in most cases. 


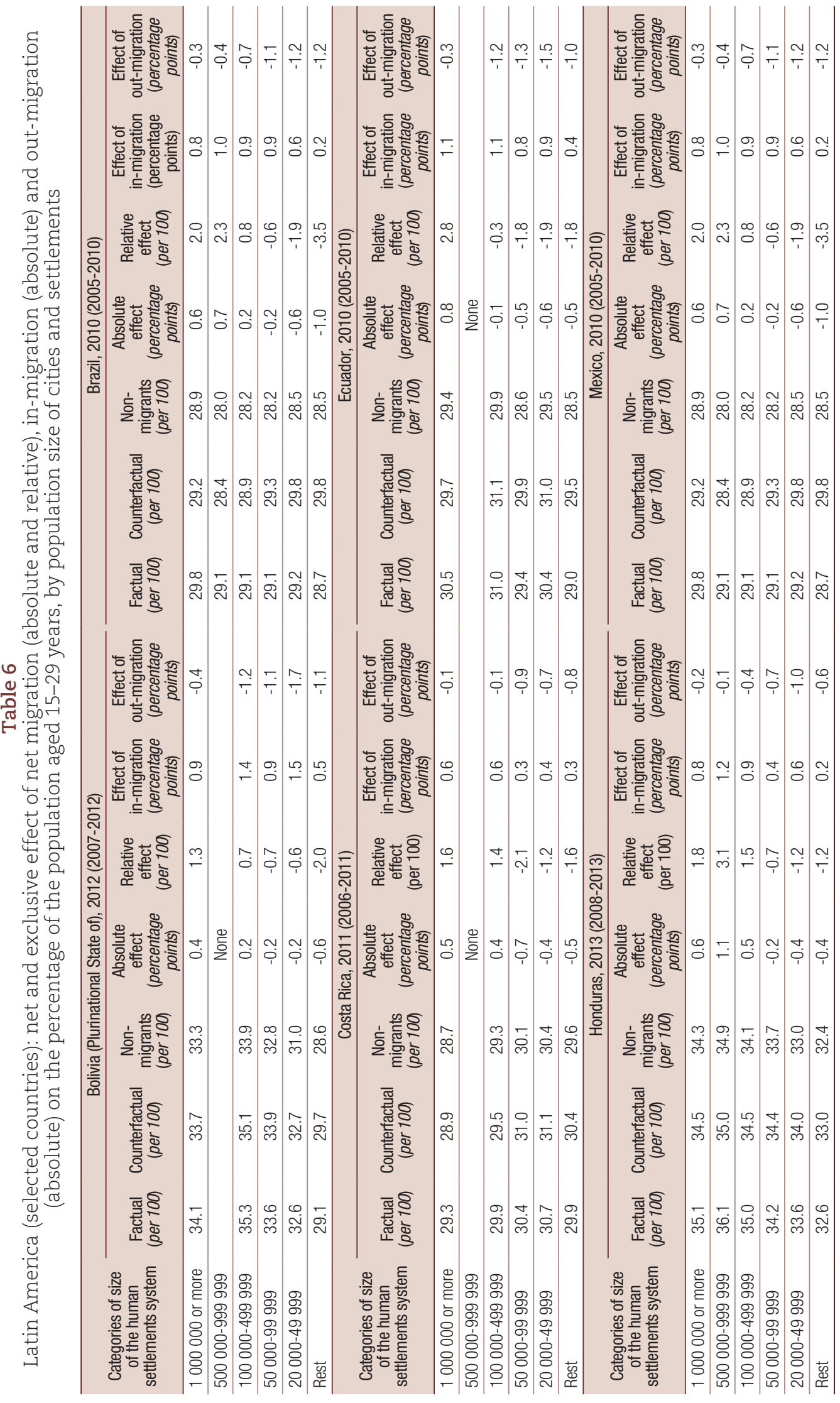




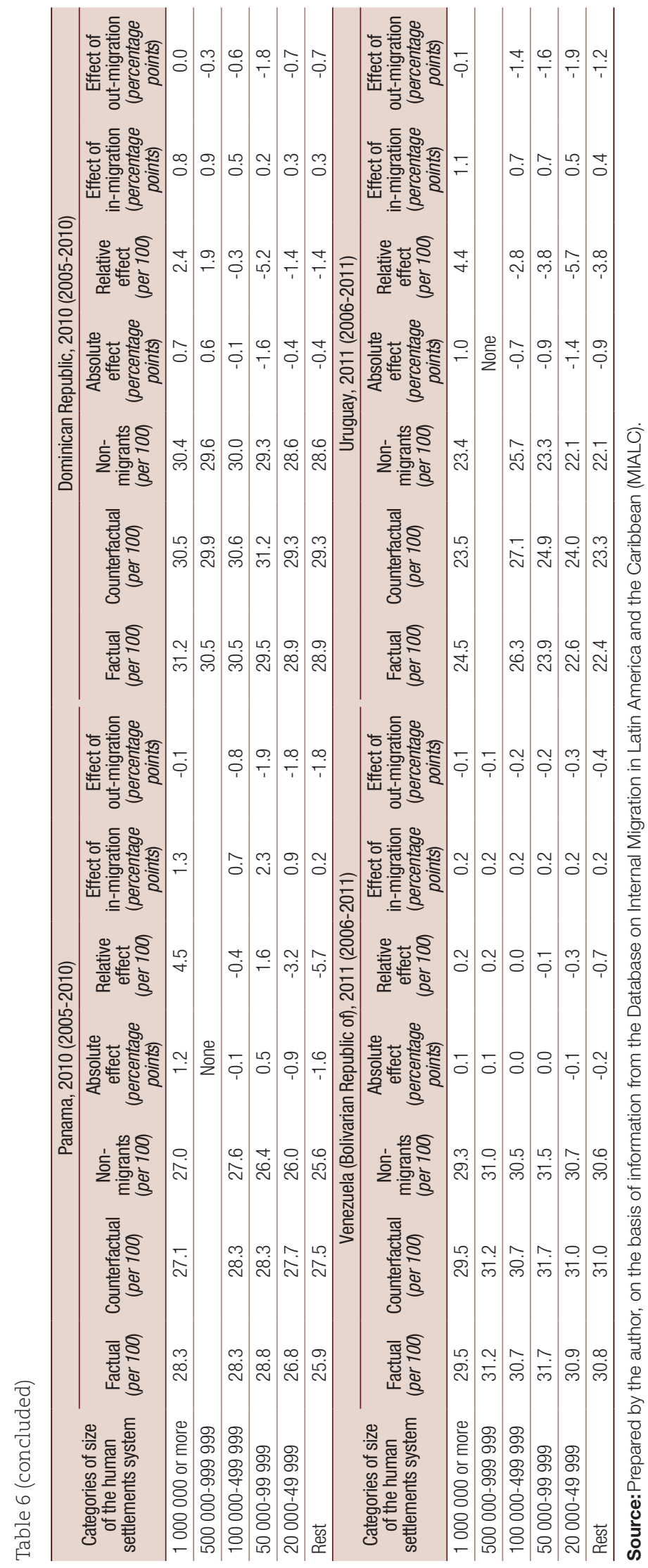




\section{Discussion and conclusions}

Three of every four migrants originate and end up in urban areas, according to the 2010 census round; a slightly higher proportion than in the 2000 census round. The average for the region -strictly speaking, for the countries included in the calculations - does not mean that there are no countries where ruralurban migration still prevails. However, these are the exception and the process is dwindling inexorably.

These results contrast with the great deficit of theory, policy, data and research on inter-city migration. The results shown here show that this oversight is unwise, because what happens in its cities is crucial for the country overall and migration reveals both strengths and weaknesses in cities, the city system or the human settlements system, and it poses challenges for policymaking and public action in general. In particular, migration is showing mixed symptoms in the case of the large cities and signs of stagnation at the base of human settlements system. At the same time, the apparent strengths of the intermediate segment will probably encounter limits and major challenges in the near future.

The slowing of in-migration to the large cities is good news, in principle, bearing in mind the complications caused by mass migration in the past. Although past migration endowed cities with muchneeded labour force at a time of strong manufacturing growth, the economic system was unable to fully absorb it. The influx also exerted heavy pressure on the infrastructure, services and governance of large cities, which national and local governments were not able to manage sustainably. The lost decade of the 1980s rapidly turned these complications into severe problems, with steep rises in poverty, high unemployment, poor public safety and urban deficits in general, including in governance. In fact, the living standards indicators obtained from censuses show that large cities no longer enjoy any obvious advantages in this regard, which has led them to slowly but steadily lose their migratory pull. Indeed, large cities today are at virtual equilibrium in terms of migration, with a still-positive rate of around 0.3 per 1,000 and subdued population growth, given that not only migration, but also fertility has fallen. Relentless migratory pressure has thus ceased to be a challenge for these cities.

Nor does this migratory quasi-equilibrium in large cities mask anomalies akin to the high rates seen at the height of the rural-urban in-migration of the 1950s to 1980s. The highest rates do not exceed a $1 \%$ annual average, and these correspond to cities with specific attractions - like Brasilia or Santa Cruz (Plurinational State of Bolivia), which combine public investment and government employment with the momentum provided by dynamic export activities in the first decade of the twenty-first century - or cities in the process of forming "metropolitan regions" with existing supercities - like Campinas or Santos in Brazil, close to the megacity of São Paulo (Cunha, 2015). Conversely, the migratory quasi-equilibrium does hide a large and growing number of cases of net out-migration. Although still a minority of cases, this group includes all the supercities (those with upwards of 10 million inhabitants) covered in the study. Thus, without there being a causal relationship, reaching the threshold of 10 million inhabitants is associated with a migratory turning point at which a city becomes an expeller. In general, this is not good news, not so much because of the direct demographic effect involved, but because of the implications: the predominance of push factors likely associated with urban and governance problems, as well as diseconomies and rising costs in these supercities. Be this as it may, net out-migration avoids migration increasing the population in these cities, which already have large number of inhabitants and serious governance issues, partly owing to their large demographic and territorial size.

Although the differential migration of women to large cities has lessened, net out-migration cities still attract women more and expel them less. The opportunities structure in the cities still offers women more options or, from the opposite perspective, the net-loss sectors of the human settlements system -that is, the lower bands - lack options for women, at least in relative terms.

In the case of age-differentiated migration, even supercities that are losing population continue to attract young people, as their opportunities structure appears to be particularly attractive for this age 
group. This phenomenon has been little studied as yet in the region, although it has been quite well documented in other parts of the world (Williamson, 1988; Florida, 2005; Pacione 2009). Its underlying causes may readily be divined: more and better options for work, study and life plans in general (including cultural consumption, finding a partner and the use of leisure time) for this age group in large cities. The concentration of tertiary education institutions in large cities increases this attraction, as do standards and paces of living that suit young people well although they may not be ideal for other age groups. The range of services and housing operations in large cities is also more suited to young people, by type if not price. Net youth in-migration contrasts with the net out-migration of other age groups, which amplifies the rejuvenating effect of internal migration on the age structure of large cities. The procedure developed by CELADE-Population Division of ECLAC shows that this last effect reinforces and extends the demographic dividend in large cities, owing to the downward pressure it exerts on the dependency index. The persistent, mass influx of young people also has other social and economic effects that are more difficult to estimate, but that various authors argue boost the economy and culture of the cities in question (Florida, 2005). Not all the effects of migration on the population composition of large cities are beneficial, however. In particular, the procedure applied in this work shows that migration reduces average levels of education in large cities, something that is not attributable to the age structure of migrants. The loss is not a significant one, but the fact that it exists at all warrants further research, at least to identify whether it reflects the in-migration of population with a low level of education, or the outmigration of population with a high level of education, a question which will be addressed in future work.

What do the data on migration reveal about medium-sized cities? Clearly, these have become consolidated as the most attractive segment in the human settlements system. This had already been noted in previous research (Rodríguez, 2011) and had been suggested by other work on the basis of population growth indices (Villa and Rodríguez, 1998). But it had not yet been demonstrated with the most recent census figures available, with concrete data that suggest a moderate pull factor not comparable to the high figures of past decades. In principle, this should ease demographic pressure on infrastructure, equipment and the various services and amenities for which cities are responsible, even though these need to keep expanding to facilitate migrants' social and labour integration and guarantee respect for their rights. The attraction of medium-sized cities is consistent with their indicators of living standards, which exceed those of large cities and far exceed those of small cities. In addition, the size of medium cities offers some governance and quality of life, which are powerful pull factors.

This said, the segment of medium-sized cities shows great diversity. In fact, there is a sharp contrast, especially among cities with between 100,000 and 499,999 inhabitants, many of which register net out-migration. It may be because they offer an immediate alternative to large cities, that the upper-medium cities (between 500,000 and 999,999 inhabitants) are the group with the highest rate of net migration and the smallest proportion of expelling cities. This is different from the case of cities with 100,000 to 499,999 inhabitants, which in the larger countries may form part of the lower segment of the cities system and show similar trends to those of small cities.

These cities also resemble the large cities in that they receive higher percentage of female and youth in-migration. In fact, in some countries, the percentage of young people has grown more in medium-sized cities than large cities as a result of migration. In addition, and unlike large cities, mediumsized cities, tend to gain in average schooling levels with migration. However, these "positive" effects are more systematic and noticeable in the case of the upper-medium cities.

In sum, their migratory pull suggests that medium-sized cities offer better socioeconomic conditions and living standards, which is borne out by the limited census data available in this respect. The effects of migration on the composition of the population tend to make these cities - especially upper-medium cities - more competitive and innovative. This is therefore a segment that benefits from in-migration and faces the challenge of administering its dividends in order to progress towards sustainable development. 
What do the data on migration reveal about the lower levels of the human settlements system, the small cities and rural areas? All three categories of the lower segment of the system used in this research (cities with between 50,000 and 99,999 inhabitants, cities with between 20,000 and 49,999 inhabitants and the "rest", a category which groups the MIADs where there are no cities of 20,000 or more inhabitants) were found to show population loss and the proportion of cities by migratory pull or push showed that the great majority registered net out-migration. In fact, this explains the paradox of having a majority of population-losing cities in a region where the process of urbanization continues exclusively owing to the - albeit decreasing - persistence of rural-urban migration.

The net out-migration registered by these parts of the settlements system is both a matter for concern and a problem. The fact that this segment does not experience the pressure of rapid growth from internal migration hides structural lags that generate net out-migration. These lags can be seen at a basic level in the indicators of living conditions calculated from census data, as well as in the poverty indices derived from the surveys, which are much higher in rural areas. Despite decades of rural exodus - which eroded the supply of migrants - and despite industrial policies aimed at renovating the primary activities that tend to be concentrated in this segment of the human settlements system, and a broad range of strategies aimed at improving and upgrading (including decentralization, local development and rural development), the indicators of well-being and access to services in this segment remain well below the rest of the human settlements system. As well, job creation is still insufficient and often not aimed at the local population, but at outside workers whose jobs do not require them to settle permanently in the area, and with income much lower than can be earned in the larger cities.

The problem lies in the fact that the bulk of the out-migration-related population loss consists of people who are younger and/or more educated than those remaining behind. As a result, this segment of the cities system is more aged and its demographic dependency ratios are much higher than natural population trends would suggest they should be. The demographic dividend is smaller and lasts for a shorter period. Out-migration is also biased towards women, whose skills still do not seem to have the space to fully develop in these localities. The only aspect of population composition that does not show stylized adverse effects is average schooling, which does not appear to depend on the age structure of migrants, since the results vary little when age is controlled for.

The "rest" segment shows a turning point in net migration (from negative to positive) in several age ranges other than young people (those aged 15-29 years). This is an interesting phenomenon, which could be interpreted as a sign of families with children returning to the rural or semirural environment. However, owing to the diversity of the "rest" category in the methodology used - which include from MIADs consisting entirely of scattered rural populations to MIADs that are in the midst of "rururbanization" but have not yet integrated with the nearest city - it is likely that this category is capturing municipalities in the process of "rururbanization" around nearby cities (Aguilar and Escanilla, 2011; Ávila, 2009; Pacione, 2009; Champion, 2008; Arroyo, 2001), especially in view of the family slant this process usually takes. This is something that should be assessed in future research, which would need to open the black box of the "rest" segment and, possibly, differentiate between distinct types of municipalities, for example between fully rural isolated municipalities and "rururban" municipalities. This would challenge the procedure used here and the databases employed for this work, which currently lack the information that would be needed to make such a distinction. More research is thus needed to identify the reasons for this emerging migratory pull.

In short, at the time of import substitution industrialization, all forces tended to favour migration towards large cities, the hubs of demand for industrialization-related labour, the best wages and supply of education, the highest levels of basic services and access to goods and services, the lowest levels of poverty, and a range of technological and cultural innovations that fed expectations of a better quality of life. Those times have changed, however, and the large cities present more contrasts than in the past. They still have pull factors, such as supply of education, skilled employment, positions of 
power and access to cutting-edge technology, but also clear push factors, such as labour informality and precarious living conditions, falling standards - and rising costs - of living and a build-up of urban deficits (ECLAC, 2012). In this context, the post-Fordist model of production and technological innovations facilitate the deconcentration of employment, at least towards the medium-sized cities, and other nodes of the cities system become economically competitive in relation to large cities. Thus they receive public and private investment which brings their infrastructure, facilities and services closer to those of the large cities, and they gain major relative advantages in terms of governance and quality of life. Nevertheless, they still lag behind in key aspects such as education, culture and recreation, where the large cities retain the lead, at least in Latin America and the Caribbean. ${ }^{10}$ Large cities also still exert a significant social and economic pull and in fact remain attractive despite their multiple problems, showing a resilience that could help them retain their key role in the future.

The competition between large and medium-sized cities takes on a different hue in the comparison with the rest of the cities system and especially with the rural segment of the human settlements system. Small cities and rural areas still suffer much more from poverty, industrial lag and lack of services and infrastructure. Factors such as the higher cost of social investment, the limited capacities and resources of local governments, the almost complete absence of higher education institutions and centres of educational excellence, the lack of skilled human resources (partly due to out-migration) and the vicious cycle of deficits that hinder the emergence of social mobility opportunities for the population still outweigh the possible advantages in terms of standard of living, safety and governance. Out-migration can thus further slow the development of the most underdeveloped segments of the human settlements system, sharpening social inequalities instead of reducing them as the prevailing theories contend (ECLAC, 2015 and 2012; Kanbur and Rappoport, 2005). Admittedly, this is only one effect and not necessarily the dominant one, because the advantages of migration for both territories -including whole countries and for individuals are well documented (ECLAC, 2012; World Bank, 2009; UNFPA, 2007; Aroca, 2004; Williamson, 1988). What is more, the emergence of a suburban or "rururban" segment composed of areas and localities with characteristics that are formally and scenically rural, but fully urban in terms of lifestyle and day-to-day links with the city, could shift the negative effects of internal migration on rural areas and small cities, as younger, better-off families move into them. This does not represent a return to the countryside, however, but the urbanization of the rural milieu.

10 In this respect, the location of universities still has a markedly metropolitan bias in almost all the countries of the region and is one of the main forces pulling young people into large cities. The incipient attempts to change this pattern have yet to be evaluated in terms of migratory impact (Rodríguez and others, 2017; Fusco and Ojima, 2016). 


\section{Bibliography}

Aguilar, A. and I. Escanilla (coords.) (2011), Periurbanización y sustentabilidad en grandes ciudades, Mexico City, Editorial M.A. Porrúa.

Alberts, J. (1977), "Migración hacia áreas metropolitanas de América Latina. Un estudio comparativo", Series E, No. 24, Santiago, Latin American Demographic Centre (CELADE).

Aroca, P. (2004), "Migración intrarregional en Chile. Modelos y resultados 1987-2002", Notas de Población, No. 78 (LC/G.2229-P), Santiago, Economic Commission for Latin America and the Caribbean (ECLAC).

Arroyo, M. (2001), "La contraurbanización: un debate metodológico y conceptual sobre la dinámica de las áreas metropolitanas", Papeles de Población, year 7, No. 30, Toluca, Center for Research and Advanced Studies of the Population, Autonomous University of the State of Mexico.

Atienza, M. and P. Aroca (2012), "Concentración y crecimiento en Chile: una relación negativa ignorada", EURE, vol. 38, No. 114, Santiago, Catholic University of Chile.

Ávila, H. (2009), "Periurbanización y espacios rurales en la periferia de las ciudades", Estudios Agrarios, No. 41, Mexico City.

Bell, M. and M. Salut (2009), "Cross-national comparisons of internal migration, human development", Technical Paper, No. 2009/30, New York, United Nations.

Berg, L. van den and others (1982), Urban Europe: A Study of Growth and Decline, vol. 1, Oxford, Pergamon Press. Brown, L. (1991), Place, Migration and Development in the Third World, London, Routledge.

Camisa, Z. (1972), "Efecto de la migración en el crecimiento y la estructura de la población de las ciudades de la América Latina", Series C, No. 139, Santiago, Latin American Demographic Centre (CELADE).

Champion, A. (2008), "The changing nature of urban and rural areas in the UK and other European countries" (UN/POP/EGM-URB/2008/07), New York, United Nations.

Cuervo, L. and J. González (1997), Industria y ciudades en la era de la mundialización. Un enfoque socioespacial, Bogota, Tercer Mundo Editores.

Cunha, J. (2015), "Dinâmica demográfica e migratória 1991-2010: realidades e mitos", A metrópole de São Paulo no século XXI: espaços, heterogeneidades e desigualdades, E. Marques (org.), Editora Unesp.

Cunha, J. and J. Rodríguez (2009), "Crecimiento urbano y movilidad en América Latina", Revista Latinoamericana de Población, No. 4-5, Latin American Population Association.

ECLAC (Economic Commission for Latin America and the Caribbean) (2015), "Panorama del desarrollo territorial en América Latina y el Caribe, 2015. Pactos para la igualdad territorial” (LC/W.671), Santiago. (2012), Population, Territory and Sustainable Development (LC/L.3474(CEP.2/3)), Santiago.

Elizaga, J. C. (1970), "Migraciones a las áreas metropolitanas de América Latina", Series E, No. 6, Santiago, Latin American Demographic Centre (CELADE).

Elizaga, J. C. and J. Macisco (1975), "Migraciones internas. Teoría, método y factores sociológicos, Series E, No. 19, Santiago, Latin American Demographic Centre (CELADE).

Florida, R. (2005), Cities and the Creative Class, New York, Routledge.

Fujita, M. and P. Krugman (2004), "The new economic geography: past, present and the future", Papers in Regional Science, vol. 83, No. 1, Wiley.

Fusco, W. and R. Ojima (2016), "Nordeste do Brasil: interiorização do ensino superior e mobilidade pendular" [online] http://187.45.187.130/ abeporgb/xxencontro/files/paper/305-117.pdf.

Geyer, M. and T. Kontuly (1993), "A theoretical foundation for the concept of differential urbanization", International Regional Science Review, vol. 15, No. 2, Sage.

Hall, P. (1996), Ciudades del mañana. Historia del urbanismo en el siglo XX, Barcelona, Ediciones del Serbal.

Henderson, J. V. (2003), "The urbanization process and economic growth: the so-what question", Journal of Economic Growth, vol. 8, No. 1, Springer.

Kanbur R. and H. Rapoport (2005), "Migration selectivity and the evolution of spatial inequality", Journal of Economic Geography, vol. 5, No. 1, Oxford University Press.

Martine, G. (1979), "Migraciones internas: ¿investigación para qué?", Notas de Población, No. 19, Santiago, Economic Commission for Latin America and the Caribbean (ECLAC).

Moultrie, T. and others (2013), Tools for Demographic Estimation, Paris, International Union for the Scientific Study of Population (IUSSP).

Pacione, M. (2009), Urban Geography. A Global Perspective, New York, Routledge. 
Rodríguez, J. (2013a), "La migración interna en las grandes ciudades en América Latina: efectos sobre el crecimiento demográfico y la composición de la población", Notas de Población, No. 96 (LC/G.2573-P), Santiago, Economic Commission for Latin America and the Caribbean (ECLAC).

(2013b), "How Is Internal Migration Reshaping Metropolitan Populations in Latin America? New Methodologies and New Evidence" [online] https://iussp.org/sites/default/files/event_call_for_papers/IUSSP2013-JRMigrationandCompositionEffectnLatinAamericaMetropolis-23-08-2013-Final.pdf.

(2011), "Migración interna y sistema de ciudades en América Latina: intensidad, patrones, efectos y potenciales determinantes, censos de la década de 2000", Población y Desarrollo series, No. 105 (LC/L.3351), Santiago, Economic Commission for Latin America and the Caribbean (ECLAC).

Rodríguez, J. and G. Busso (2009), Migración interna y desarrollo en América Latina entre 1980 y 2005. Un estudio comparativo con perspectiva regional basado en siete países, Libros de la CEPAL, No. 102 (LC/G.2397-P), Santiago, Economic Commission for Latin America and the Caribbean (ECLAC).

Rodríguez, J. and others (2017), “¿Perdió el Área Metropolitana del Gran Santiago su atractivo? Sí, pero no. Un examen basado en datos y procedimientos novedosos para la estimación de la migración interna y sus efectos durante el periodo 1977-2013", EURE, vol. 43, No. 128, Santiago, Catholic University of Chile.

Rogers, A. and L. Castro (1982), "Patrones modelo de migración", Demografía y Economía, vol. 16, No. 3, Mexico City.

Romero, J. L. (1976), Latinoamérica: las ciudades y las ideas, Buenos Aires, Siglo XXI.

Sassen, S. (2007), "El reposicionamiento de las ciudades y regiones urbanas en una economía global: ampliando las opciones de políticas y gobernanza", Revista Latinoamericana de Estudios Urbano Regionales (EURE), vol. 33, No. 100, Santiago, Catholic University of Chile.

Srinivasan, S. and A. Rodríguez (2016), "Pobreza y desigualdades rurales. Perspectivas de género, juventud y mercado de trabajo", Desarrollo Productivo series, No. 206 (LC/L.4206), Santiago, Economic Commission for Latin America and the Caribbean (ECLAC).

UNFPA (United Nations Population Fund) (2007), State of World Population 2007. Unleashing the Potential of Urban Growth, New York.

United Nations (2015), World Urbanization Prospects: The 2014 Revision (ST/ESA/SER.A/366), New York.

Villa, M. (1991), "Introducción al análisis de la migración: apuntes de clase: notas preliminares", Series B, No. 91 (LC/DEM/R.164), Santiago, Latin American and Caribbean Demographic Centre (CELADE)Population Division of ECLAC.

Villa, M. and J. Alberts (1980), "Redistribución espacial de la población en América Latina", Series E, No. 28, Santiago, Latin American Demographic Centre (CELADE).

Villa, M. and J. Rodríguez (1998), "Distribución espacial de la población, urbanización y ciudades intermedias: hechos en su contexto", Ciudades intermedias de América Latina y el Caribe: propuesta para la gestión urbana (LC/L.1117), R. Jordán and D. Simioni, Santiago, Economic Commission for Latin America and the Caribbean (ECLAC).

(1997), "Dinámica sociodemográfica de las metrópolis latinoamericanas durante la segunda mitad del siglo XX", Notas de Población, No. 65 (LC/DEM/G.177), Santiago, Economic Commission for Latin America and the Caribbean (ECLAC).

Welti, C. (ed.) (1997), Demografía I, Mexico City, Latin American Programme of Population Activities/National Autonomous University of Mexico (UNAM).

Williamson, J. (1988), "Migrant selectivity, urbanization, and industrial revolutions", Population and Development Review, vol. 14, No. 2, New York, Population Council.

(1965), "Regional inequality and the process of national development: a description of the patterns", Economic Development and Cultural Change, vol. 13, No. 4, Chicago, The University of Chicago Press.

World Bank (2009), World Development Report 2009: Reshaping Economic Geography. Overview, Washington, D.C. 